\title{
Stability of the mandible following advancement: A comparison of three postsurgical fixation techniques
}

\author{
Edward Ellis III, DDS, MS," Steve Reynolds, DDS,"* and David S. Carlson, PhD ${ }^{\star \star \star}$ \\ Dallas, Texas, and Ann Arbor, Mich.
}

This study examines short-term stability of the mandible following mandibular advancement surgery by means of three standard techniques of postsurgical fixation. Twenty-two adult female rhesus monkeys (Macaca mulatta) underwent sagittal ramus advancement osteotomy of approximately 4 to $6 \mathrm{~mm}$. Six animals had dental maxillomandibular fixation alone. Six animals had dental plus skeletal maxillomandibular fixation with circummandibular wires connected to pyriform aperture wires. Ten animals had rigid internal fixation with bicortical bone screws between the proximal and distal segments without maxillomandibular fixation. Radiographic cephalograms with the aid of tantalum bone markers and dental amalgams were analyzed during the first 6 postoperative weeks to evaluate skeletal and dental stability. Rigid internal fixation and the use of dental p/us skeletal maxillomandibular fixation were both equally effective in the prevention of postsurgical relapse. However, in the animals in which only dental maxillomandibular fixation was used, statistically significant changes (relapse) occurred when compared with either of the other groups. (AM J ORTHOD DENTOFAC ORTHOP 1988;94:38-49.)

\section{$\mathrm{U}$} ntil relatively recently all of the studies that examined the stability of mandibular advancement surgery used maxillomandibular fixation (MMF) as the means of postsurgical stabilization of the skeletal segments. In all of these studies, the dentition was used to secure MMF and varying amounts of relapse were noted. ${ }^{1-10}$ The postsurgical relapse that occurred following mandibular advancement surgery was found to occur during three general time intervals, each with its own unique set of causes. Relapse occurring months to years after the surgical procedure was shown to be caused by condylar osteolysis and remodeling. ${ }^{12,13}$ If relapse occurred on release of MMF, it was thought to be caused by condylar distraction or inadequate healing of the skeletal components.

A particular form of relapse is that occurring during the immediate postoperative period of MMF. In fact,

From the University of Michigan

Research supported by NIH-NIDR Grants DE-06874 and DE05232, and grants from the University of Michigan School of Dentistry and Chalmers J. Lyons Academy of Oral Surgery-James R. Hayward Research Fund.

*Associate Professor, Division of Oral and Maxillofacial Surgery, University of Texas.

**Resident, Oral and Maxillofacial Surgery, University of Michigan.

***Associate Professor, Departments of Orthodontics and Anatomy \& Cell Biology; Associate Research Scientist, The Center for Human Growth and Development, University of Michigan. most cases of relapse have been shown to occur during this time period; few cases have been found to occur thereafter. ${ }^{9,10}$ It now is clear that distracting muscle and connective tissues exert posteriorly directed forces on the advanced distal mandibular segment, causing relapse. ${ }^{14}$ The suprahyoid muscle complex has been shown to be a primary factor in short-term relapse, and an experimental study has shown that greater stability can be achieved by suprahyoid myotomy at the time of mandibular advancement. ${ }^{14}$

The condition that has permitted the stretched soft tissues to exert their detrimental effects was provided when the dentition was used to secure MMF. One of the primary functions of the periodontal ligament is remodeling of the alveolar bone in response to forces placed on the teeth. Alveolar remodeling permitted posterior translation of the distal mandibular segment after mandibular advancement surgery in response to the forces placed on this scgment by the soft tissues, which were stretched with mandibular advancement. We have shown that bypassing the dentition and directly securing the distal mandibular segment to the maxilla with skeletal suspension wires will reduce or prevent skeletal relapse after mandibular advancement surgery. ${ }^{15,16} \mathrm{We}$ have shown also that the suprahyoid complex will adapt to lengthening brought about by mandibular advancement surgery; it does so primarily at the connective 
tissue attachments of the muscle. ${ }^{17}$ Thus, if the distal mandibular segment is held firmly in the advanced position until osseous union of the skeletal segments occurs, nonrelapsing osteotomy can be achieved.

In recent years the use of rigid internal fixation for postsurgical inmobilization of the proximal and distal segments following sagittal ramus advancement osteotomies has been popularized. It is possible that this may be another means to firmly secure the distal segment of the advanced mandible in its forward position until osseous union and adaptation of the suprahyoid complex have occurred. Preliminary reports show that this mode of fixation is very stable, with little postsurgical relapse occurring. ${ }^{18-20}$

The purpose of this investigation was to compare the short-term effectiveness of rigid internal fixation with other more routine techniques of fixation to hold the advanced mandible in its new position. This study concerned itself only with the first 6 postoperative weeks because this is the period during which most cases of relapse have been shown to occur when maxillomandibular fixation techniques are used. ${ }^{3-11}$ It is also during the first 6 postoperative weeks that adaptations within the suprahyoid complex have been found to take place. ${ }^{17}$

\section{MATERIALS AND METHODS Experimental animals}

Twenty-two adult female rhesus monkeys (Macaca mulatta) were used in this experiment. All animals had full dentitions with third molars in occlusion.

The monkeys were randomly divided into three experimental groups on the basis of the method of fixation used following mandibular advancement surgery. Animals in group DF (dental fixation, $n=6$ ) underwent mandibular advancement of two molar cusps and were placed in MMF using dental fixation only. Animals in group $\mathrm{SF}$ (skeletal fixation, $\mathrm{n}=6$ ) underwent an identical surgical procedure, but were placed in MMF using both skeletal and dental fixation. Animals in group RF (rigid fixation, $n=10$ ) underwent mandibular advancement of 1 to 1.5 molar cusps, but had the proximal and distal segments secured with bicortical bone screws. Animals in group RF were not placed into MMF.

\section{Presurgical protocol}

Immediately following release from quarantine, each animal received radiopaque tantalum bone markers in prescribed locations throughout the craniofacial region. Small dental amalgams also were placed in the facial surface of the left maxillary and mandibular teeth.
The maxillary and mandibular incisor teeth were extracted with standard oral surgical techniques several weeks before mandibular advancement surgery. This procedure was necessary to facilitate feeding during the period of MMF for animals in groups DF and SF. From this point the animals were fed a soft mash diet to condition them to the diet they received during MMF.

Ten days before the surgical procedure, dental impressions were taken and models were prepared and articulated to effect mandibular advancement of approximately 4 to $6 \mathrm{~mm}$. An acrylic interocclusal wafer was fabricated to lock the teeth into this new relationship. Standard lateral cephalograms were obtained for all animals.

\section{Surgical procedure}

The surgical procedure used for groups DF and SF was described previously ${ }^{16}$ and involves a standard sagittal ramus osteotomy with slight modifications for use in the rhesus monkey. In these two groups, the osteotomy was extended to just behind the mental foramen to ensure bone contact after the relatively large advancement. This amount of advancement was not possible in group RF because the areas of the proximal and distal segments in which the bone screws must be inserted are not in intimate contact, and usually are 2 to $3 \mathrm{~mm}$ apart. Therefore, the osteotomy in group RF animals was extended only to where the external oblique ridge blended with the mandibular corpus.

Once the mandible was split bilaterally, one of three types of fixation was used. In the animals in groups DF and SF, the maxillary and mandibular teeth were bonded into the interocclusal splint with orthodontic composite resin after pumicing and acid-etching the teeth. In addition, skeletal suspension wires were placed in group SF animals (circummandibular to piriform aperture). Following MMF the proximal and distal segments were joined with a wire placed at the inferior border.

In group RF animals, rigid internal fixation was applied. The technique consisted of the application of temporary MMF by wiring together the maxillary and mandibular dentitions with the interocclusal splint in place, followed by the application of three $2-\mathrm{mm}$ bone screws bilaterally. The procedure used was exactly as described by Jeter, Van Sickels, and Dolwick. ${ }^{21}$ The temporary MMF was released and the position of the mandible checked. The acrylic splint was then bonded to the maxillary dentition to provide a stable biteplane on which the mandibular teeth could occlude in the postsurgical period. There were no deep indentations of the mandibular cusps into the maxillary splint; the 
Table I. Horizontal displacement of mandibular symphysis (mm)

\begin{tabular}{|c|c|c|c|c|c|c|c|c|c|c|c|c|c|c|}
\hline \multirow[b]{3}{*}{ Group } & \multicolumn{14}{|c|}{ Changes from one time period to next } \\
\hline & \multicolumn{2}{|c|}{ Prepost } & \multicolumn{2}{|c|}{ Post-l wk } & \multicolumn{2}{|c|}{$1-2 w k$} & \multicolumn{2}{|c|}{$2-3 w k$} & \multicolumn{2}{|c|}{$3-4 w k$} & \multicolumn{2}{|c|}{$4-5 w k$} & \multicolumn{2}{|c|}{$5-6 w k$} \\
\hline & $\bar{X}$ & $S D$ & $\bar{X}$ & $S D$ & $\bar{X}$ & $S D$ & $\bar{X}$ & $S D$ & $\bar{X}$ & $S D$ & $\bar{X}$ & $S D$ & $\vec{X}$ & $S D$ \\
\hline $\begin{array}{l}\text { Group DF }(n=6) \\
\text { Significance }\end{array}$ & $\begin{array}{l}6.57 \\
+\dagger \dagger\end{array}$ & 1.65 & -0.33 & 1.01 & $\begin{array}{c}-0.60 \\
\ddagger \neq\end{array}$ & 0.71 & $\begin{array}{c}-0.16 \\
\text { 柿 }\end{array}$ & 0.73 & $\begin{array}{c}-0.29 \\
\ddagger \neq *\end{array}$ & 0.34 & $\begin{array}{c}-0.14 \\
\text { 接 }\end{array}$ & 0.41 & $\begin{array}{c}-0.31 \\
\ddagger \ddagger\end{array}$ & 0.48 \\
\hline $\begin{array}{l}\text { Group SF }(n=6) \\
\text { Significance }\end{array}$ & $\begin{array}{l}6.41 \\
+\dagger \dagger\end{array}$ & 1.58 & -0.09 & 0.39 & 0.15 & 0.53 & 0.09 & 0.44 & 0.04 & 0.29 & 0.33 & 0.87 & -0.37 & 0.78 \\
\hline $\begin{array}{l}\text { Group RF }(n=10) \\
\text { Significance }\end{array}$ & $\begin{array}{c}4.54 \\
+\dagger \dagger * *\end{array}$ & 1.26 & -0.07 & 0.20 & -0.02 & 0.21 & 0.15 & 0.24 & 0.04 & 0.18 & 0.03 & 0.15 & -0.20 & 0.52 \\
\hline
\end{tabular}

$\dagger$ Significant change from previous time interval within same group $(\dagger=0.05$ level, $\dagger \dagger=0.01$ level, $\dagger \dagger \dagger=0.001$ level of confidence). $¥$ Significant change from immediate postoperative value within same group ( $\neq=0.05$ level, $\neq \ddagger=0.01$ level, $\neq \ddagger \neq=0.001$ level of confidence).

*Significantly different from other experimental groups $\left(^{*}=0.05\right.$ level, ${ }^{* *}=0.01$ level, ${ }^{* * *}=0.001$ level of confidence).

Table II. Vertical displacement of mandibular symphysis (mm)

\begin{tabular}{|c|c|c|c|c|c|c|c|c|c|c|c|c|c|c|}
\hline \multirow[b]{3}{*}{ Group } & \multicolumn{14}{|c|}{ Changes from one time period to next } \\
\hline & \multicolumn{2}{|c|}{ Prepost } & \multicolumn{2}{|c|}{ Post-1 wk } & \multicolumn{2}{|c|}{$1.2 w k$} & \multicolumn{2}{|c|}{$2-3 w k$} & \multicolumn{2}{|c|}{$3-4 w k$} & \multicolumn{2}{|c|}{ 4-5wk } & \multicolumn{2}{|c|}{$5-6 w k$} \\
\hline & $\overline{\bar{X}}$ & $S D$ & $\overline{\bar{X}}$ & $S D$ & $\overline{\bar{x}}$ & $S D$ & $\bar{X}$ & $S D$ & $\overline{\bar{X}}$ & SD & $\overline{\bar{X}}$ & $S D$ & $\bar{X}$ & $S D$ \\
\hline $\begin{array}{l}\text { Group DF }(n=6) \\
\text { Significance }\end{array}$ & $\begin{array}{c}3.29 \\
+1+\end{array}$ & 0.66 & 0.63 & 0.68 & $\begin{array}{l}0.31 \\
\neq\end{array}$ & 0.38 & $\begin{array}{l}0.18 \\
+\end{array}$ & 0.74 & $\begin{array}{l}0.22 \\
\ddagger^{*}\end{array}$ & 0.22 & $\begin{array}{c}0.24 \\
\ddagger \ddagger *\end{array}$ & 0.40 & $\begin{array}{c}0.07 \\
f \neq\end{array}$ & 0.11 \\
\hline $\begin{array}{l}\text { Group SF }(n=6) \\
\text { Significance }\end{array}$ & $\begin{array}{l}3.25 \\
+t+\end{array}$ & 1.04 & 0.27 & 0.50 & $\begin{array}{c}-0.26 \\
*\end{array}$ & 0.33 & 0.59 & 0.33 & -0.16 & 0.28 & -0.19 & 0.30 & 0.01 & 0.18 \\
\hline $\begin{array}{l}\text { Group RF }(n=10) \\
\text { Significance }\end{array}$ & $\begin{array}{l}2.64 \\
+\dagger+*\end{array}$ & 1.19 & -0.18 & 0.62 & 0.06 & 0.17 & -0.11 & 0.17 & 0.01 & 0.15 & 0.00 & 0.13 & 0.06 & 0.15 \\
\hline
\end{tabular}

$\dagger$ Significant change from previous time interval within same group $(\dagger=0.05$ level, $\dagger \dagger=0.01$ level, $\dagger \dagger \dagger=0.001$ level of confidence) . $\ddagger$ Significant change from immediate postoperative value within same group $(\ddagger=0.05$ level, $\ddagger \ddagger=0.01$ level, $\ddagger \ddagger \neq=0.001$ level of confidence) *Significantly different from other experimental groups $\left(^{*}=0.05\right.$ level, ${ }^{* *}=0.01$ level, ${ }^{* * *}=0.001$ level of confidence).

splints were ground flat until the only contacts were the centric stops.

\section{Postsurgical protocol}

Each animal was radiographed immediately after the surgical procedure and returned to its cage. In taking the radiographs in group RF animals, a single rubber band was placed around the crown of the head, passing under the mandibular body to hold the mandible into occlusion with the maxillary splint. Procaine penicillin $\mathrm{G}(40,000 \mathrm{U} / \mathrm{kg})$ was given preoperatively and continued for 7 days following the surgical procedure. Postoperative analgesics were given at the discretion of the veterinarian. All animals were given the same standard mash diet and fresh fruit, Tang, and water ad libitum. The skeletal wire fixation (group SF) was tightened periodically, if noted to be loose.

\section{Cephalometric analytic techniques}

Lateral cephalograms of each animal were taken immediately preoperatively, immediately postoperatively, and at weekly intervals for 6 postoperative weeks. The serial tracings were digitized at the Craniofacial Biology Laboratory, The University of Michigan School of Dentistry. Change in the position of the distal mandibular segment was determined by measuring the horizontal and vertical displacement of a bone marker in the mandibular symphysis relative to a cranial reference line (CRL). The CRL is a line parallel to the preoperative occlusal plane drawn through a sphenoidal (cranial base) bone marker in the preoperative radiograph. This line was transferred to subsequent tracings by computer.

Change in the relationship between the proximal and distal mandibular segments was determined by measuring the angle formed by two lines - one drawn through two bone markers within the mandibular corpus (anterior to the osteotomy) and one through two bone markers in the mandibular ramus (posterior to the osteotomy) (see Fig, 3).

Change in the mandibular plane angle (MPA) was evaluated by measuring the angle between the CRL and a line drawn through two bone markers within the mandibular body anterior to the osteotomy (see Fig. 4). 


\begin{tabular}{c|c|c|c|c|c}
\hline \multicolumn{6}{c}{ Interval changes } \\
\hline \multicolumn{2}{c|}{ Post-2 $w k$} & \multicolumn{2}{c}{ Post-4 wk } & \multicolumn{2}{c}{ Post-6 wk } \\
\hline $\bar{X}$ & $S D$ & $\bar{X}$ & $S D$ & $\bar{X}$ & $S D$ \\
\hline $\begin{array}{c}-0.93 \\
* * * \\
0.05\end{array}$ & 0.37 & $\begin{array}{c}-1.38 \\
* * *\end{array}$ & 1.00 & $\begin{array}{c}-1.84 \\
* * *\end{array}$ & 0.81 \\
-0.09 & 0.30 & 0.10 & 0.71 & 0.07 & 0.49 \\
& 0.10 & 0.38 & 0.09 & 0.62 \\
\hline
\end{tabular}

\begin{tabular}{l|c|c|c|c|c}
\hline \multicolumn{7}{c|}{ Interval changes } \\
\hline \multicolumn{2}{c|}{ Post-2 wk } & \multicolumn{2}{c}{ Post-4 $w k$} & \multicolumn{2}{c}{ Post-6 wk } \\
\hline $\bar{X}$ & $S D$ & $\bar{X}$ & $S D$ & $\bar{X}$ & $S D$ \\
\hline $\begin{array}{l}\text { 0.95 } \\
* *\end{array}$ & 0.54 & $\begin{array}{c}1.34 \\
* *\end{array}$ & 1.05 & $\begin{array}{c}1.65 \\
* * *\end{array}$ & 0.89 \\
0.01 & 0.29 & -0.10 & 0.50 & -0.27 & 0.52 \\
-0.12 & 0.52 & -0.22 & 0.58 & -0.17 & 0.58 \\
\hline
\end{tabular}

Changes in the vertical position of the maxillary and mandibular teeth within their respective jaws were made with the aid of the dental amalgam fillings. The perpendicular distance between the amalgam filling in the maxillary first premolar and the CRL was computed for each film. The perpendicular distance between the amalgam filling in the mandibular first premolar and a line between a bone marker in the mandibular symphysis and one in the posterior aspect of the mandibular body was similarly computed.

\section{Statistical analysis}

To identify changes within each experimental group, the paired $t$ test was used to determine the significance of changes from 1 week to the next and to determine changes between each weekly time period and the immediate postoperative values. A significant result indicates that the difference between the values at the two time periods is statistically different from 0 . Pearson's correlation coefficients were calculated for the variables to determine whether postsurgical relapse (horizontal and vertical) could be correlated with the amount of surgical change.

To identify differences among the three experimen- tal groups, the profile analysis (multivariate analysis of variance on increments between successive time points) was used. A significant result indicated that the three curves are not parallel and therefore at least one of the groups behaved differently over time. Analysis of covariance also was used to determine the significance of changes for all weekly time periods and the time intervals postoperatively to 2 weeks, 4 weeks, and 6 weeks, with the initial surgical change in the specific variable as the covariate. Using the initial surgical change as the covariate helped to eliminate any bias induced by the smaller advancement in group RF animals. A significant result indicated that the three experimental groups behaved differently.

\section{RESULTS}

All 22 animals withstood the surgical procedure well. There were no major infections or postoperative complications in any of the experimental animals. The MMF was stable throughout the follow-up period in groups DF and SF.

\section{Horizontal displacement of symphysis}

The avcrage anterior horizontal surgical displacement of the mandibular symphysis was approximately $6.5 \mathrm{~mm}( \pm 1.6)$ in groups DF and SF, and $4.5 \mathrm{~mm}$ $( \pm 1.3)$ in group RF (Table I). The amount of horizontal advancement was significantly less in group RF when compared with the other two groups $(P<0.01)$. Throughout the next 6 weeks, group DF animals showed a progressive posterior displacement (relapse) of the symphysis (Fig. 1, A), whereas the animals in groups SF and RF showed almost no change at all (Fig. 1, $B$ and $C$ ). The hypothesis of parallelism of the profiles of the three experimental groups was rejected by the profile analysis $(P<0.001)$. The posterior displacement (relapse) in group DF animals reached significance by the second postoperative week. From this point on, there was a significant amount of horizontal relapse in comparison with the immediate postoperative value $(P<0.001)$. When the three groups were compared, a significant difference between group DF and the two other experimental groups occurred at the $2-, 4-$, and 6-week intervals $(P<0.001)$. By the sixth postoperative week, group DF had a mean relapse of $1.8 \mathrm{~mm}$ ( $28 \%$ of the $6.57-\mathrm{mm}$ advancement). Although there were no statistically significant differences between groups SF and RF in any postsurgical time period, group RF showed much less variability in the horizontal position of the mandibular symphysis than did group SF (compare Fig. 1, $B$ and $C$ ). There was no significant correlation between the amount of surgical advancement and postsurgical relapse in any of the experimental groups. 

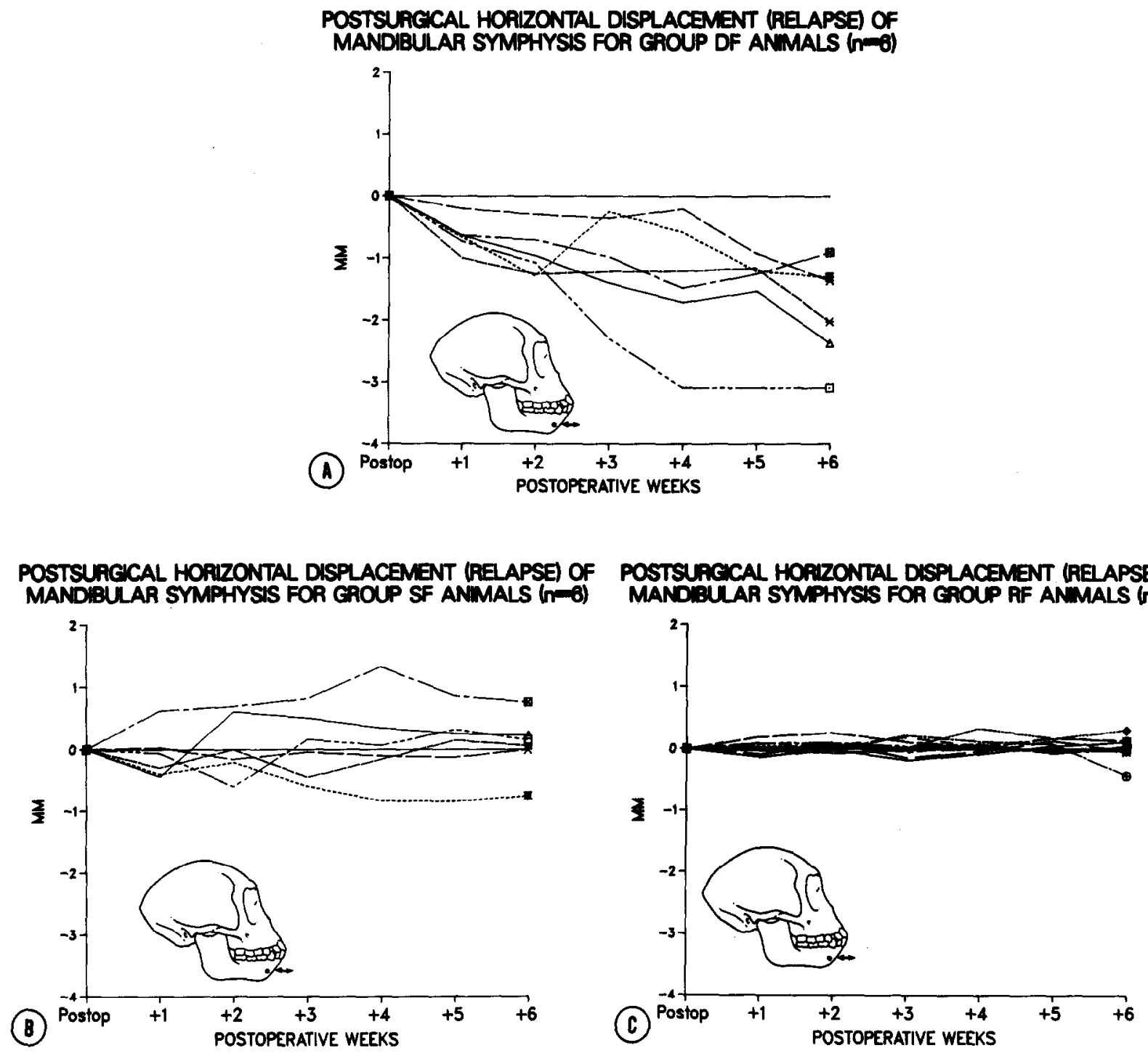

Fig. 1. Graph of the postsurgical change in the horizontal position of the mandibular symphysis for group DF (A), group SF (B), and group RF (C). The immediate postoperative value was set as "0" in these graphs. Note that all animals in group DF had some postoperative relapse, whereas the animals in groups SF and RF had almost none.

\section{Vertlcal displacement of symphysis}

The average inferior vertical surgical displacement was approximately $3.25 \mathrm{~mm}$ in groups DF and SF, and $2.6 \mathrm{~mm}$ in group RF (Table II). The vertical displacement was significantly less in group RF than in the other two groups $(P<0.05)$. Throughout the next 6 weeks, the symphysis continued to move inferiorly in group DF animals (Fig. 2, $A$ ), whereas in group SF animals, a very slight superior displacement was noted (Fig. 2, B). The hypothesis of parallelism of the profiles of the three experimental groups was rejected at the 0.001 level by the profile analysis. The vertical position of the mandibular symphysis remained stable in group RF animals throughout the follow-up period
(Fig. 2, C). The continued inferior displacement in group DF animals was of such magnitude that by the second postoperative week, a significant difference from the immediate postoperative value had occurred $(P<0.05)$. When the three groups were compared, a significant difference between group DF and the two other experimental groups occurred at the 2-, 4-, and 6 -week intervals $(P<0.01,0.01$, and 0.001 , respectively). By the sixth postoperative week, the mandibular symphysis in group DF had moved inferiorly $1.65 \mathrm{~mm}$ beyond the $3.3 \mathrm{~mm}$ obtained at surgery. There was no significant correlation between the surgical change and the magnitude of postsurgical change in the vertical position of the symphysis. 


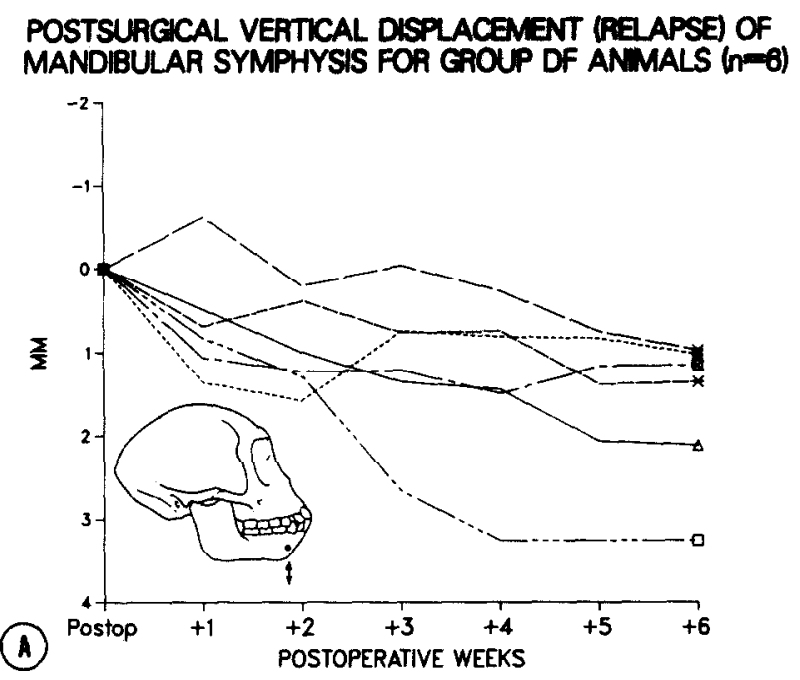
POSTSUPCCAL VERTCAL DISPLACEMENT RREAPSE) OF
MANDBUALA SYIMPYYSIS FOR GROUP SF ANIMALS (n-6) POSTSURGCAL VERTICAL DISPLACEMENT (RELAPSE) OF
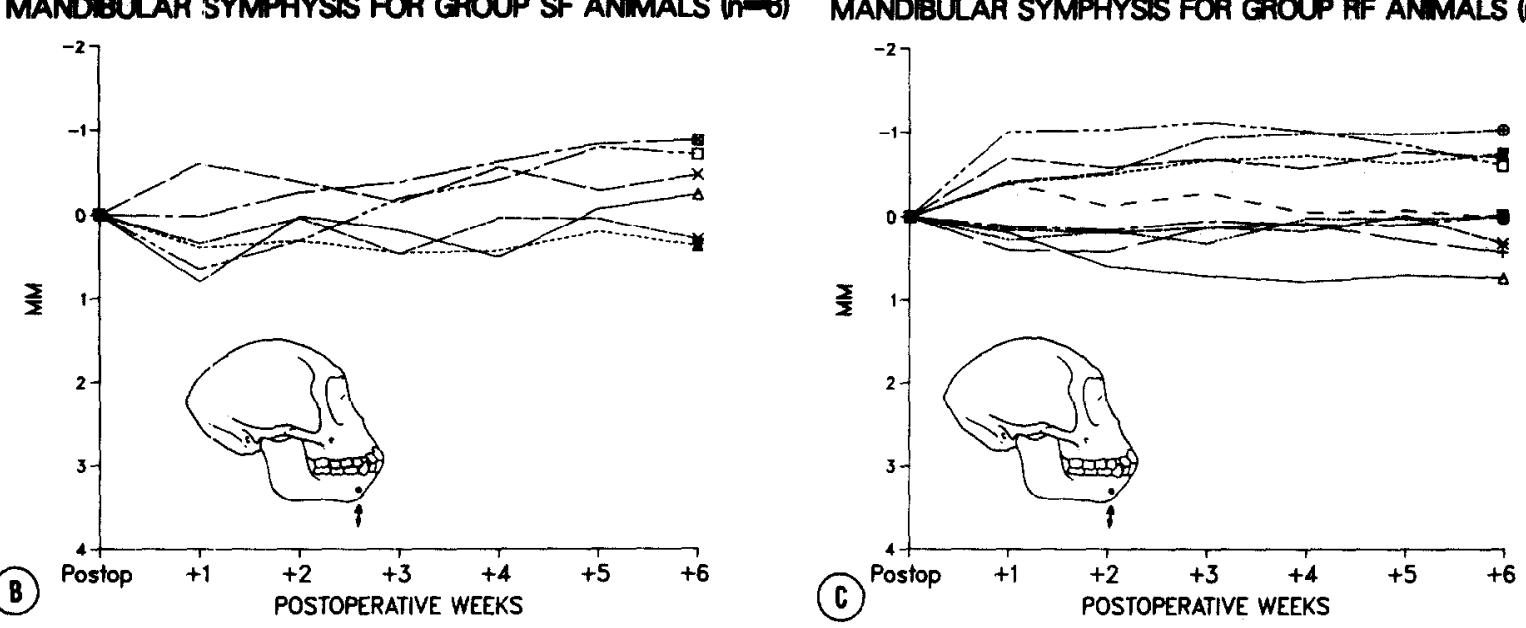

Fig. 2. Graph of the postsurgical change in the vertical position of the mandibular symphysis for grcup DF (A), group SF (B), and group RF (C). The immediate postoperative value was set as " 0 " in graphs. Note that all animals in group DF had some postoperative vertical displacement inferiorly, grcup SF had some superior displacement, and group RF had almost no displacement.

\section{Change in the ramus-corpus angle}

The mean angle between the proximal and distal segments changed very slightly with surgical advancement of the mandible (Table III). However, in the postoperative time periods, changes were noted. The hypothesis of parallelism of the profiles of the three experimental groups was rejected at the 0.001 level by the profile analysis. The angle increased steadily throughout the 6 postoperative weeks in group DF, such that by 6 weeks, an average increase of almost $11^{\circ}$ had occurred (Fig. 3). By the second postoperative week, group DF showed values that were significantly greater than the immediate postoperative value $(P<0.05)$. In groups $\mathrm{SF}$ and $\mathrm{RF}$, there were very small changes in this angle throughout the postsurgical period. At the 2- and 4-week intervals, group RF had significantly less change than the other two experimental groups. However, at the 6-week interval, group DF had significantly greater change in this angle than the other two groups.

\section{Change in the mandibular plane angle}

On average the angle between the CRL and the mandibular corpus changed little with surgical treatment (Table IV). However, in the postoperative period, group DF animals showed a progressive increase in the MPA, such that by the sixth postoperative week, a mean increase of $6^{\circ}$ had occurred (Fig. 4). This was a statistically significant difference from the other experimental groups at the 2-week $(P<0.05)$, 4-week $(P<0.01)$, and 6-week $(P<0.01)$ intervals. The hy- 


\section{MEAN POSTOPERATIVE CHANCE IN MANDIBULAR RAMUS-CORPUS ANCLE FOR EXPERIMENTAL GROUPS}

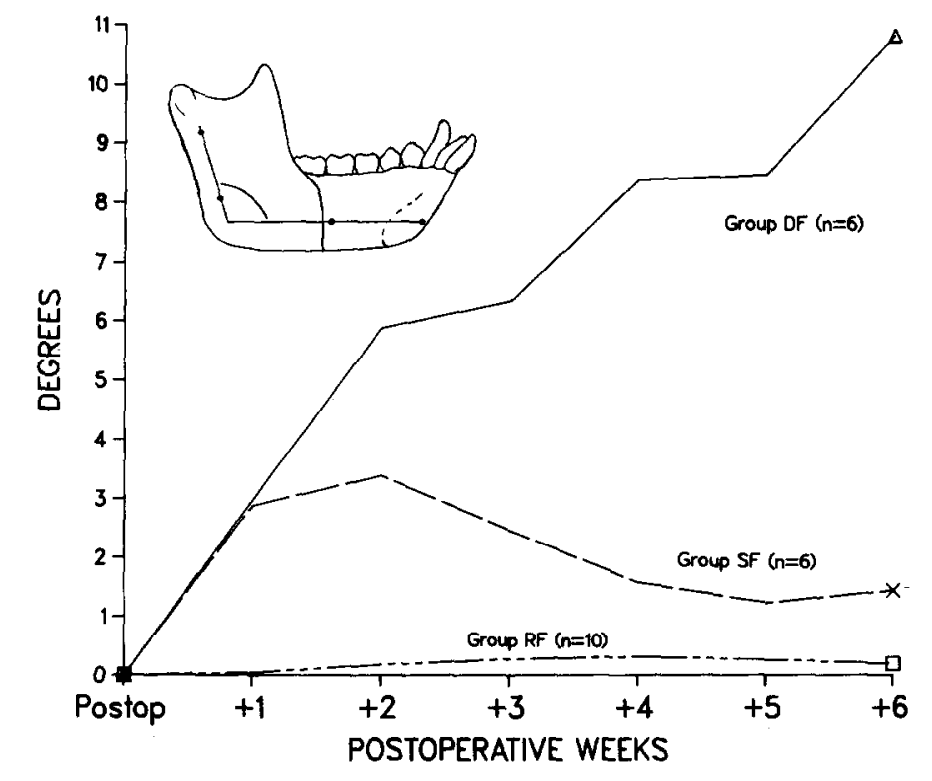

Fig. 3. Graph of the mean postsurgical change in the angle between the mandibular ramus and corpus for all three experimental groups. The postoperative measure was chosen as " 0 " and postsurgical changes were plotted from this baseline.

\section{MEAN POSTOPERATIVE CHANCE IN MANDIBULAR PLANE ANGLE FOR EXPERIMENTAL GROUPS}

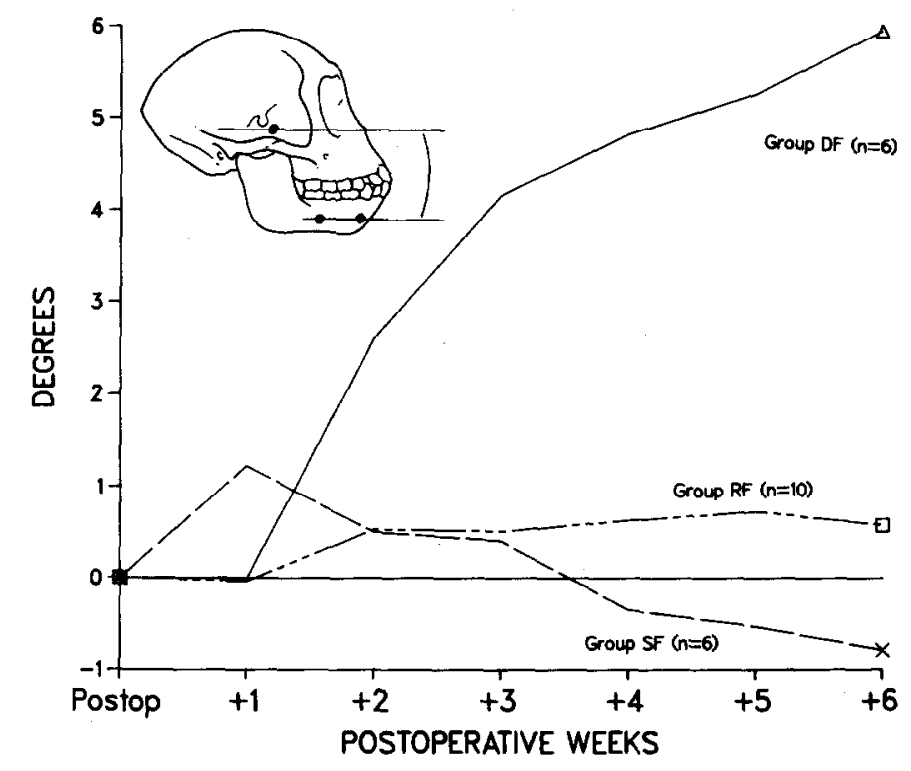

Fig. 4. Graph of the mean postsurgical change in mandibular plane angle for all three experimental groups. The postoperative measure was chosen as " 0 " and postsurgical changes were plotted from this baseline. Note the continuous increase in group DF.

pothesis of parallelism of the profiles of the three experimental groups was rejected at the 0.001 level by the profile analysis. Most of the increase in MPA in group DF occurred in the second and third postoperative weeks during which a significant difference from the other experimental groups, from the preceding time intervals, and from immediate postoperative values had occurred. Groups SF and RF showed little change in the MPA in the postoperative time periods, and were not significantly different from one another. 


\section{MEAN VERTICAL DISPLACEMENT OF MAXILLARY FIRST BICUSPID FOR EXPERIMENTAL GROUPS}

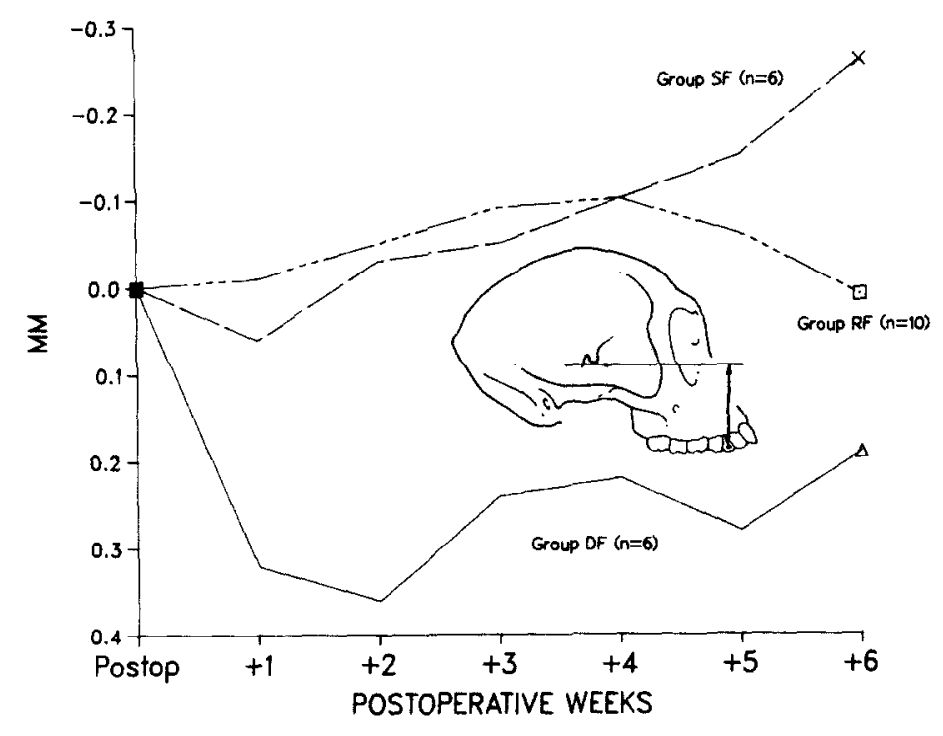

Fig. 5. Graph of the mean postsurgical change in the vertical position of the maxillary first premolar tooth for all three experimental groups. The postoperative measure was chosen as " 0 " and postsurgical changes were plotted from this baseline. Note the extrusion in group DF animals and slight intrusion in group SF animals. Group RF showed very little change.

\section{MEAN VERTICAL DIBPLACENENT OF MANDBBULAR FIRST BICUSPD FOR EXPERTIENTAL CAOUPS}

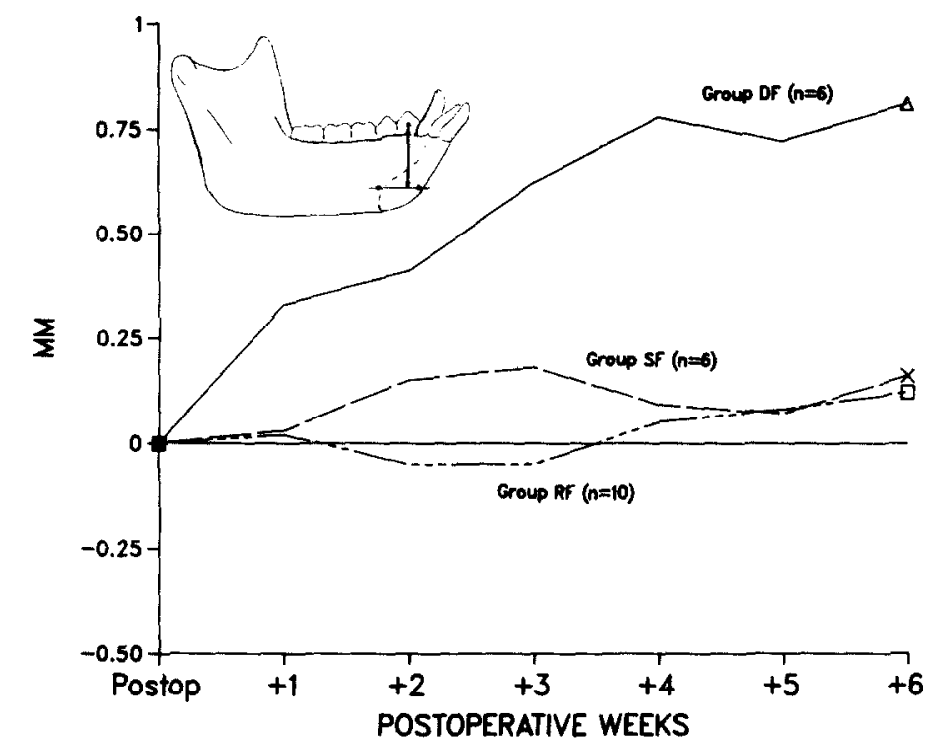

Fig. 6. Graph of the mean postsurgical change in the vertical position of the mandibular first premolar toisth for all three experimental groups. The immediate postoperative measure was chosen as " 0 " and pcstsurgical changes were plotted from this baseline. Note the marked extrusion that occurred during the first 3 postoperative weeks in group DF animals and the relative stability in groups SF and RF.

\section{Vertical displacement of maxillary first premolar}

The maxillary first premolar changed very little in vertical position from pre- to postoperatively (Table V). In the ensuing time periods, groups $\mathrm{SF}$ and $\mathrm{RF}$ showed almost no change in the vertical position of the max- illary first premolar (Fig. 5), although there was an overall small intrusion in group SF animals (not significant). Group DF, however, showed slight extrusion, stabilizing around $0.25 \mathrm{~mm}$ of extrusion by the third postoperative week. None of the changes from 1 week 
Table III. Change in mandibular ramus-corpus angle $\left(^{\circ}\right.$

\begin{tabular}{|c|c|c|c|c|c|c|c|c|c|c|c|c|c|c|}
\hline \multirow[b]{3}{*}{ Group } & \multicolumn{14}{|c|}{ Changes from one time period to next } \\
\hline & \multicolumn{2}{|c|}{ Prepost } & \multicolumn{2}{|c|}{ Post-l wk } & \multicolumn{2}{|c|}{$1-2 w k$} & \multicolumn{2}{|c|}{$2-3 w k$} & \multicolumn{2}{|c|}{$3-4 w k$} & \multicolumn{2}{|c|}{$4.5 w k$} & \multicolumn{2}{|c|}{$5-6 w k$} \\
\hline & $\bar{X}$ & $S D$ & $\bar{X}$ & $S D$ & $\bar{X}$ & $S D$ & $\bar{X}$ & $S D$ & $\bar{X}$ & $S D$ & $\bar{X}$ & $S D$ & $\vec{X}$ & $S D$ \\
\hline $\begin{array}{l}\text { Group DF }(n=6) \\
\text { Significance }\end{array}$ & -0.94 & 4.7 & 2.98 & 7.52 & $\begin{array}{c}2.90 \\
\ddagger\end{array}$ & 3.89 & $\begin{array}{c}-0.45 \\
\ddagger\end{array}$ & 2.82 & $\begin{array}{l}2.05 \\
\ddagger *\end{array}$ & 2.03 & $\begin{array}{l}0.09 \\
\ddagger \ddagger\end{array}$ & 2.97 & $\begin{array}{l}2.36 \\
\neq \ddagger\end{array}$ & 2.61 \\
\hline $\begin{array}{l}\text { Group SF }(n=6) \\
\text { Significance }\end{array}$ & 0.06 & 4.6 & 2.88 & 5.30 & 0.50 & 2.42 & -0.92 & 1.49 & -0.89 & 2.71 & -0.34 & 2.54 & 0.21 & 3.17 \\
\hline $\begin{array}{l}\text { Group RF }(n=10) \\
\text { Significance }\end{array}$ & 0.02 & 3.61 & 0.04 & 0.71 & 0.14 & 0.42 & 0.09 & 0.61 & 0.04 & 0.63 & -0.05 & 0.20 & -0.07 & 0.38 \\
\hline
\end{tabular}

$\dagger$ Significant change from previous time interval within same group $(\dagger=0.05$ level, $\dagger \dagger=0.01$ level, $\dagger \dagger \dagger=0.001$ level of confidence) . $\ddagger$ Significant change from immediate postoperative value within same group $(\ddagger=0.05$ level, $\ddagger \neq=0.01$ level, $\neq \neq \ddagger=0.001$ level of confidence). *Significantly different from other experimental groups $\left(*=0.05\right.$ level, ${ }^{* *}=0.01$ level, ${ }^{* * *}=0.001$ level of confidence).

Table IV. Change in mandibular plane angle $\left(^{\circ}\right)$

\begin{tabular}{|c|c|c|c|c|c|c|c|c|c|c|c|c|c|c|}
\hline \multirow[b]{3}{*}{ Group } & \multicolumn{14}{|c|}{ Changes from one time period to next } \\
\hline & \multicolumn{2}{|c|}{ Prepost } & \multicolumn{2}{|c|}{ Post $-I$ wk } & \multicolumn{2}{|c|}{$1-2 w k$} & \multicolumn{2}{|c|}{$2-3 w k$} & \multicolumn{2}{|c|}{$3-4 w k$} & \multicolumn{2}{|c|}{$4-5 w k$} & \multicolumn{2}{|c|}{$5.6 w k$} \\
\hline & $\bar{X}$ & $S D$ & $\overline{\bar{X}}$ & $S D$ & $\bar{X}$ & $S D$ & $\bar{X}$ & $S D$ & $\bar{X}$ & $S D$ & $\bar{X}$ & $S D$ & $\overline{\bar{X}}$ & $S D$ \\
\hline $\begin{array}{l}\text { Group DF }(n=6) \\
\text { Significance }\end{array}$ & 0.29 & 4.26 & -0.01 & 5.31 & $\begin{array}{c}2.61 \\
+\neq *\end{array}$ & 4.31 & $\begin{array}{c}1.55 \\
+\dagger *\end{array}$ & 2.38 & $\begin{array}{l}0.67 \\
\ddagger^{*}\end{array}$ & 1.02 & $\begin{array}{l}0.45 \\
\neq\end{array}$ & 0.91 & $\begin{array}{l}0.69 \\
\dagger \dagger\end{array}$ & 1.02 \\
\hline $\begin{array}{l}\text { Group SF }(n=6) \\
\text { Significance }\end{array}$ & -0.68 & 4.40 & 1.22 & 3.41 & -0.72 & 1.65 & -0.10 & 0.75 & -0.75 & 0.73 & -0.18 & 1.46 & -0.26 & 0.99 \\
\hline $\begin{array}{l}\text { Group RF }(n=10) \\
\text { Significance }\end{array}$ & 1.56 & 2.38 & -0.04 & 1.30 & 0.57 & 0.43 & -0.02 & 0.55 & 0.12 & 0.44 & 0.10 & 0.47 & -0.15 & 0.57 \\
\hline
\end{tabular}

$\dagger$ Significant change from previous time interval within same group $(\dagger=0.05$ level, $\uparrow \dagger=0.01$ level, $\dagger \dagger \dagger=0.001$ level of confidence) . $\ddagger$ Significant change from immediate postoperative value within same group $(\ddagger=0.05$ level, 㧊 $=0.01$ level, $\neq$ 抹 $=0.001$ level of confidence) . *Significantly different from other experimental groups $\left(^{*}=0.05\right.$ level, ${ }^{* *}=0.01$ level, $* * *=0.001$ level of confidence).

Table V. Vertical displacement of maxillary first premolar (mm)

\begin{tabular}{|c|c|c|c|c|c|c|c|c|c|c|c|c|c|c|}
\hline \multirow[b]{3}{*}{ Group } & \multicolumn{14}{|c|}{ Changes from one time period to next } \\
\hline & \multicolumn{2}{|c|}{ Prepost } & \multicolumn{2}{|c|}{ Post-1 wk } & \multicolumn{2}{|c|}{$1-2 w k$} & \multicolumn{2}{|c|}{$2-3 w k$} & \multicolumn{2}{|c|}{$3-4 w k$} & \multicolumn{2}{|c|}{$4-5 w k$} & \multicolumn{2}{|c|}{$5-6 w k$} \\
\hline & $\bar{X}$ & $S D$ & $\bar{X}$ & $S D$ & $\bar{X}$ & $S D$ & $\bar{X}$ & $S D$ & $\bar{X}$ & $S D$ & $\bar{X}$ & $S D$ & $\vec{X}$ & $S D$ \\
\hline $\begin{array}{l}\text { Group DF }(n=6) \\
\text { Significance }\end{array}$ & 0.27 & 0.38 & 0.32 & 0.57 & 0.04 & 0.31 & -0.12 & 0.53 & -0.02 & 0.37 & 0.06 & 0.29 & -0.09 & 0.18 \\
\hline $\begin{array}{l}\text { Group SF }(n=6) \\
\text { Significance }\end{array}$ & 0.20 & 0.30 & 0.06 & 0.34 & -0.09 & 0.49 & -0.02 & 0.13 & -0.05 & 0.45 & -0.05 & 0.25 & -0.11 & 0.27 \\
\hline $\begin{array}{l}\text { Group RF }(n=10) \\
\text { Significance }\end{array}$ & -0.15 & 0.33 & -0.01 & 0.22 & -0.04 & 0.25 & -0.04 & 0.17 & -0.01 & 0.21 & 0.04 & 0.25 & 0.07 & 0.22 \\
\hline
\end{tabular}

$\dagger$ Significant change from previous time interval within same group $(\dagger=0.05$ level, $\uparrow \dagger=0.01$ level, $\uparrow \dagger \dagger=0.001$ level of confidence) .

$\ddagger$ Significant change from immediate postoperative value within same group $(\$=0.05$ level, $\neq=0.01$ level, $\neq \ddagger \ddagger=0.001$ level of confidence).

$*$ Significantly different from other experimental groups $\left(^{*}=0.05\right.$ level, $* *=0.01$ level, $* * *=0.001$ level of confidence).

to the next or from immediately postoperative to succeeding time periods were significantly different from 0 in any experimental group. However, group DF showed a significant amount of extrusion when compared with the other experimental groups in the 2-, 4-, and 6-week intervals $(P<0.05)$.

\section{Vertical displacement of the mandibular first premolar}

Slight extrusion of the mandibular first premolar occurred to some extent in all experimental groups from pre- to postoperatively (Table VI). In the next 6 weeks, there was little change in the vertical position of the 


\section{DISCUSSION}

\begin{tabular}{|c|c|c|c|c|c|}
\hline \multicolumn{6}{|c|}{ Interval changes } \\
\hline \multicolumn{2}{|c|}{ Post-2 wk } & \multicolumn{2}{|c|}{ Post-4 wk } & \multicolumn{2}{|c|}{ Post-6 wk } \\
\hline $\bar{X}$ & $S D$ & $\bar{X}$ & $S D$ & $\vec{X}$ & $S D$ \\
\hline 5.88 & 4.80 & 8.38 & 5.44 & $\begin{array}{c}10.83 \\
* *\end{array}$ & 4.13 \\
\hline 3.37 & 4.86 & 1.57 & 4.68 & 1.44 & 4.52 \\
\hline $\begin{array}{c}0.18 \\
*\end{array}$ & 0.62 & $\begin{array}{l}0.31 \\
*\end{array}$ & 0.81 & 0.19 & 1.34 \\
\hline
\end{tabular}

Numerous clinical investigators have suggested that soft-tissue tension in general, and the suprahyoid musculature in particular play a major role in skeletal relapse following mandibular advancement surgery. ${ }^{1,4,6-9,22,23}$ The net effect of this tension is thought to be displacement of the distal mandibular segment posteriorly, resulting in relapse. ${ }^{14,24}$ Although most surgeons agree that undue stretching of the soft tissues and suprahyoid muscle complex contributes to skeletal relapse following mandibular advancement surgery, there is no unanimity of opinion regarding the most effective way to alleviate adverse effects of soft-tissue stretch. Overcorrection of the mandibular movement, ${ }^{1,25.26}$ use of a shoulder-chin brace or cervical collar, ${ }^{1,2,4-6,8-10}$ and detachment of the suprahyoid musculature ${ }^{22,26}$ have all been proposed as prophylactic therapy to alleviate relapse tendencies. The results of an experimental investigation in Macaca mulatta showed that suprahyoid myotomy is an effective method to prevent relapse following mandibular advancement. ${ }^{14}$

The use of a shoulder-chin brace is based on the premise that if the distal mandibular segment can be held in the advanced position until soft tissues have adapted, stability can be optimized. Inherent in this hypothesis is the assumption that the suprahyoid muscular complex and soft tissues have the ability to adapt to lengthening. A recent experimental investigation by Carlson, Ellis, and Dechow ${ }^{17}$ found that the suprahyoid muscle complex can indeed adapt to lengthening caused by mandibular advancement surgery. Therefore, the hypothesis that relapse can be negated if the mandible can be held in its new position until the adaptations have occurred seems to have merit. Besides the use of shoulder-chin braces, other methods offered as means to achieve the same result are skeletal fixation ${ }^{22,23,25}$ and rigid internal fixation. ${ }^{18-20}$ In their most ideal form, these methods would rigidly hold the distal mandibular segment in its postsurgical position until osseous healing between the proximal and distal segments occurs. The dentition, with the adaptive periodontal ligament, would be bypassed, preventing migration of the teeth through the alveolar bone and thus inhibiting skeletal relapse.

The results of this study indicate that skeletal stability can be achieved by using either skeletal fixation in the form of circummandibular wires attached to pyriform aperture wires or rigid internal fixation. No hor-

mandibular first premolar in the animals in groups SF and RF (Fig. 6). Group DF animals, however, showed progressive extrusion of this tooth throughout the period of MMF. There was a significant extrusion in group DF when compared with the other experimental groups at the 4.- and 6-week intervals $(P<0.05)$. izontal relapse was found in this study when either of these modalities was used for fixation. Conversely, in the animals whose mandibles were secured with dental MMF only, a mean relapse of $28 \%$ of the total horizontal advancement occurred in the first 6 postoperative weeks. The relapse experienced in group DF animals 
Table VI. Vertical displacement of mandibular first premolar $(\mathrm{mm})$

\begin{tabular}{|c|c|c|c|c|c|c|c|c|c|c|c|c|c|c|}
\hline \multirow[b]{3}{*}{ Group } & \multicolumn{14}{|c|}{ Changes from one time period to next } \\
\hline & \multicolumn{2}{|c|}{ Prepost } & \multicolumn{2}{|c|}{ Post-1 wk } & \multicolumn{2}{|c|}{$1-2 w k$} & \multicolumn{2}{|c|}{$2-3 w k$} & \multicolumn{2}{|c|}{$3-4 w k$} & \multicolumn{2}{|c|}{$4-5 w k$} & \multicolumn{2}{|c|}{$5-6 w k$} \\
\hline & $\bar{X}$ & $S D$ & $\bar{X}$ & $S D$ & $\bar{X}$ & $S D$ & $\bar{X}$ & $S D$ & $\bar{X}$ & $S D$ & $\bar{X}$ & $S D$ & $\bar{X}$ & $S D$ \\
\hline $\begin{array}{l}\text { Group DF }(n=6) \\
\text { Significance }\end{array}$ & 0.33 & 0.50 & 0.08 & 0.80 & 0.21 & 0.56 & $\begin{array}{c}0.16 \\
\ddagger\end{array}$ & 0.42 & $\begin{array}{l}0.23 \\
\$\end{array}$ & 0.35 & $\begin{array}{c}-0.06 \\
\ddagger\end{array}$ & 0.24 & $\begin{array}{c}0.09 \\
\ddagger\end{array}$ & 0.21 \\
\hline $\begin{array}{l}\text { Group SF }(n=6) \\
\text { Significance }\end{array}$ & 0.11 & 0.43 & 0.03 & 0.29 & 0.12 & 0.40 & 0.03 & 0.27 & -0.09 & 0.39 & -0.02 & 0.27 & 0.09 & 0.28 \\
\hline $\begin{array}{l}\text { Group RF }(n=10) \\
\text { Significance }\end{array}$ & 0.26 & 0.25 & 0.02 & 0.20 & -0.07 & 0.19 & 0.00 & 0.18 & 0.10 & 0.19 & 0.03 & 0.23 & 0.04 & 0.23 \\
\hline
\end{tabular}

$\dagger$ Significant change from previous time interval within same group $(\dagger=0.05 \mathrm{lcvel}, \dagger \dagger=0.01 \mathrm{lcvel}, \uparrow \dagger \dagger=0.001$ level of confidence). $\ddagger$ Significant change from immediate postoperative value within same group $(\ddagger=0.05$ level, $\ddagger \ddagger=0.01$ level, $\ddagger \ddagger \neq=0.001$ level of confidence). *Significantly different from other experimental groups $\left(^{*}=0.05\right.$ level, ${ }^{* *}=0.01$ level, $* * *=0.001$ level of confidence).

compares similarly to clinical studies of mandibular advancement when the teeth were used to secure the postsurgical position of the mandible. For example, relapse during the period of fixation was found to be $26 \%$ by Lake and co-workers, ${ }^{9} 45 \%$ by Will and colleagues, ${ }^{10}$ and $30 \%$ by Smith, Moloney, and West ${ }^{11}$ in large samples of mandibular advancements in which the dentition was used to secure maxillomandibular fixation. Conversely, a clinical study by Ellis and Gallo, ${ }^{15}$ using skeletal wire fixation in addition to dental maxillomandibular fixation, showed significantly less horizontal relapse $(9 \%)$ than any of the above studies in which only dental MMF was used. In addition, the reports in which rigid internal fixation was used showed almost no horizontal relapse. ${ }^{18-20}$

The results of this investigation also showed a statistically significant postsurgical inferior displacement of the symphysis that was progressive in group DF animals during the 6 postoperative weeks. Further, the mandibular plane angle continued to increase in this group throughout the experimental period. No such inferior displacement of the symphysis and increase in mandibular plane angle were found in the animals in groups SF and RF. The probable reason for these findings is that the suprahyoid musculature and soft tissue tension tend to pull the distal mandibular segment both posteriorly and inferiorly in group DF. The mechanism by which this occurs is extrusion of the teeth, causing a further increase in the vertical position of the anterior mandible, as noted by the results of this study and those of Lake and co-workers, ${ }^{9}$ and Will and colleagues ${ }^{10}$ during the period of MMF.

A report by Van Sickels, Larsen, and Thrash ${ }^{19}$ indicated that relapse was consistently found in mandibular advancements larger than $6 \mathrm{~mm}$ using rigid internal fixation. This is a particularly distressing finding because relapse following rigid internal fixation (as opposed to relapse occurring during the period of MMF) will result in an alteration of the occlusal relationship. One may question what structural alterations are occurring to result in these findings. There are three possible areas in which structural alterations could result in relapse following mandibular advancement with rigid internal fixation. The first is at the osteotomy site itself. If the bicortical bone screws did not provide absolute rigidity between the proximal and distal segments, the distal segment could translate posteriorly. This would indicate that the bone screws are being bodily translated through at least one cortical plate of bone. A second means by which relapse could occur is from a more posterior articulation of the condyle. This possibility should not be surprising because it has been shown that the stretched soft tissues following advancement of the mandible contribute to skeletal relapse. ${ }^{14,24}$ Because the mandible is not wired to the maxilla during the initial postsurgical period when adaptations within the soft tissues usually occur, ${ }^{17}$ all of the tension within the stretched soft tissues must be generated through the TMJ. Distalization of the condyle would then be expected and, on the basis of the same cause, condylar osteolysis could result in postsurgical relapse. It is also possible that a combination of all three of these mechanisms of postsurgical relapse are operational.

Within the limits of the present study, the use of three bicortical bone screws proved a stable means to secure the proximal and distal segments of the mandible following advancement in group RF animals. There was no change in the angle between the corpus and the ramus in the postoperative period, and no relapse in group RF animals. One may question, however, whether the mandibles were advanced sufficiently to produce the necessary amount of tension within the soft tissues to result in clinically significant relapse. The mean advancement in group RF animals was $2 \mathrm{~mm}$ less than the mean advancement in the other two experimental groups. Perhaps, less relapse would have occurred in group DF 


\begin{tabular}{|c|c|c|c|c|c|}
\hline \multicolumn{6}{|c|}{ Interval changes } \\
\hline \multicolumn{2}{|c|}{ Post-2 wk } & \multicolumn{2}{|c|}{ Post -4 wk } & \multicolumn{2}{|c|}{ Post-6 wk } \\
\hline $\bar{x}$ & $S D$ & $\bar{X}$ & $S D$ & $\bar{X}$ & $S D$ \\
\hline 0.29 & 0.46 & $\begin{array}{c}0.68 \\
*\end{array}$ & 0.54 & $\begin{array}{c}0.71 \\
*\end{array}$ & 0.38 \\
\hline 0.15 & 0.40 & 0.08 & 0.36 & 0.15 & 0.40 \\
\hline-0.05 & 0.13 & 0.05 & 0.22 & 0.12 & 0.31 \\
\hline
\end{tabular}

with a smaller advancement. Ellis and Carlson ${ }^{14}$ showed that mandibular advancement of approximately 4 to $4.5 \mathrm{~mm}$ in five adult rhesus monkeys resulted in 13\% mean relapse when the teeth were used to secure MMF (5.5 mm increase in mandibular length $\simeq 4.5 \mathrm{~mm}$ horizontal advancement). Thus, a smaller amount of relapse might be expected in group RF animals because of the smaller mean advancement.

On the basis of the results of and within the limits of this study, skeletal suspension wires (in addition to dental MMF) and rigid internal fixation are both considered excellent methods to provide postsurgical stabilization following advancement of the mandible. It should not be inferred, however, that the use of rigid internal fixation will necessarily provide stable means of fixation in large advancements because the monkey model used in this study did not lend itself to the study of large advancements of the mandible.

We would like to thank Vicki LaRoche and Drs. Kathleen H. Mayo and Mike Powers for their assistance with the technical aspects of this study, and Charles Kowalski for his assistance with the statistical analysis.

\section{REFERENCES}

1. Poulton DR, Ware WH. Surgical-orthodontic treatment of severe mandibular retrusion. AM J ORTHOD 1971;59:244-65.

2. Poulton DF, Ware WH. Surgical-orthodontic treatment of severe mandibular retrusion. Part II. AM J ORTHOD 1973;63:237-55.

3. McNeill $R^{\prime} W$. Skeletal relapse duuring intermaxillary fixation after surgical mandibular advancement. Proceedings of the Third International Congress of the European Orthodontic Society, 1973.

4. McNeill RW, Hooley JR, Sundberg RJ. Skeletal relapse during intermaxillary fixation. J Oral Surg 1973;31:212-27.

5. Guernsey L.. Stability of treatment results in Class II malocclusion corrected by full mandibular advancement surgery. Oral Surg Oral Med Oral Pathol 1974;37:668-87.

6. Ive J, McNiill RW, West RA. Mandibular advancement: skeletal and dental shanges during fixation. J Oral Surg 1977;35:881.

7. Kohn MW. Analysis of relapse after mandibular advancement surgery. J Oral Surg 1978;36:676-84.
8. Poulton DR, Ware WH, Baumrind S, Crane D. Surgical mandibular advancement studied with computer-aided cephalometrics. AM J ORTHOD 1979;76:121-35.

9. Lake SL, McNeill RW, Little RM, West RA. Surgical mandibular advancement: a cephalometric analysis of treatment responses. AM J ORTHOD 1981;80:376-94.

10. Will LA, Joondeph R, West RA, Hohl TH. Condylar position following mandibular advancement: its relationship to relapse. J Oral Maxillofac Surg 1984;42:578-88.

11. Smith GC, Moloney FB, West RA. Mandibular advancement surgery. A study of the lower border wiring technique for osteosynthesis. Oral Surg Oral Med Oral Pathol 1985;60:467-75.

12. Phillips RM, Bell WH. Atrophy of the mandibular condyles after sagittal ramus osteotomy: report of case. J Oral Surg 1978;36:45.

13. Worms FW, Spiedel TM, Bevis RR, Waite DE. Posttreatment stability and esthetics of orthognathic surgery. Angle Orthod 1980;50:251.

14. Ellis E, Carlson DS. Stability two years after mandibular advancement with and without suprahyoid myotomy: an experimental study. J Oral Maxillofac Surg 1983;41:426.

15. Ellis E, Gallo WJ. Relapse following mandibular advancement with dental plus skeletal maxillomandibular fixation. J Oral Maxillofac Surg 1986;44:509.

16. Mayo KH, Ellis E. Stability of mandibular advancement using dental plus skeletal maxillomandibular fixation. $J$ Oral Maxillofac Surg 1987;45:243.

17. Carlson DS, Ellis E, Dechow PC. Adaptation of the suprahyoid muscle complex to mandibular advancement surgery. АM J ORTHOD DENTOFAC ORTHOP 1987;92:134-43.

18. Van Sickels JE, Flanary CM. Stability associated with mandibular advancement treated by rigid internal fixation. J Oral Maxillofac Surg 1985;43:338-41.

19. Van Sickels JE, Larsen AJ, Thrash WJ. Relapse after rigid fixation of mandibular advancement. J Oral Maxillofac Surg 1986;44:698.

20. Thomas PM, Tucker MR, Prewitt JR, Proffit WR. Early skeletal and dental changes following mandibular advancement and rigid internal fixation. Adult J Orthod Orthogn Surg 1986;3:171.

21. Jeter TS, Van Sickels JE, Dolwick MF. Rigid internal fixation of ramus osteotomies. J Oral Maxillofac Surg 1984;42:270.

22. Epker BN, Wolford LM, Fish LC. Mandibular deficiency syndrome. Surgical considerations for mandibular advancement. Oral Surg Oral Med Oral Pathol 1978;45:349-63.

23. Schendel SA, Epker BN. Results after mandibular advancement surgery: an analysis of 87 cases. J Oral Surg 1980;38:265.

24. Carlson DS, Ellis E, Schneiderman ED, Ungerleider JC. Experimental models of surgical intervention in the growing face: cephalometric analysis of facial growth and relapse. In: McNamara JA Jr, Carlson DS, Ribbens KA, eds. The effect of surgical intervention on craniofacial growth. Monograph 12 , Craniofacial Growth Series. Ann Arbor, 1982. Center for Human Growth and Development. University of Michigan.

25. Epker BN, Wessberg GA. Mechanisms of early skeletal relapse following advancement of the mandible. $\mathrm{Br} \mathrm{J}$ Oral Surg 1982;20:175.

26. Steinhauser EW. Advancement of the mandible by sagittal ramus split and suprahyoid myotomy. J Oral Surg 1973;31:516-21.

Reprint requests to:

Dr. Edward Ellis III

University of Texas, Southwest Medical Center

Division of Oral and Maxillofacial Surgery

5323 Harry Hines Blvd.

Dallas, TX 75235 